[From the Laboratories of Physiological Chemistry of the UNIVERsity of ILLINOIS AND OF JEFFERSON MEDICAL COLIEGE.]

\title{
STUDIES ON WATER DRINKING. XVII. THE AMMONIA OUT- PUT AS AN INDEX OF THE STIMULATION OF GASTRIC SECRETION FOLLOWING WATER INGESTION.
}

\author{
By F. WILLS AND P. B. HaWK. \\ Received November 12, 1913.
}

It is apparent from the literature, so far as we have been able to determine, that Heidenhain ${ }^{1}$ was the first authority to advance the view that water stimulated the flow of gastric juice. Somewhat later Sanotskii ${ }^{2}$ came to the same conclusion. It remained, however, for Pavlov ${ }^{3}$ and his collaborators to place this important physiological-chemical fact upon a firmer experimental foundation. By the use of dogs possessing the Pavlov stomach they showed that the ingestion of $400-500 \mathrm{cc}$. Of water stimulated the flow of gastric juice, and moreover that this stimulation was chemical in character rather than of nervous origin, inasmuch as it was effective following the severing of the vagus nerves. Their experimental data indicate that they were unable, in several instances, to dem. onstrate any stimulatory power for small volumes of water, $i$. $e$, Ioo$150 \mathrm{cc}$. They concluded, therefore, that "a prolonged and widely spread contact" with the gastric mucosa was essential for the most efficient stimulation.

Rather more definite data, which are of a wider physiological significance than are those of Pavlov and his collaborators, have been submitted by Foster and Lambert. ${ }^{4}$ Dogs provided with Pavlov stomachs were utilized. It was observed when large volumes of water were included in the dietary of the animals that the orifice of the small stomach invariably "appeared raw and inflamed" upon the following day, whereas when the water ingestion of the animals was maintained at a low level, these pronounced indications of irritation were not in evidence. These observations led the authors, in question, to investigate the influence of the water content of the diet upon the secretion of gastric juice. It was found that volumes of water below $200 \mathrm{cc}$. exerted no appreciable or uniform stimulation. When larger volumes were fed, however, e. g., $40 \mathrm{cc}$. per $\mathrm{kg}$. body weight, a marked increase in the flow of gastric juice was in evidence. This increase was moreover proportional to the volume of water ingested. The efficiency of water was shown likewise in connection with certain milk feeding tests. In one instance the volume of juice secreted upon feeding $500 \mathrm{cc}$. of milk, concentrated by evaporation to

1 Pfiuger's Arch., 19, I48 (1879).

2. Arch. sci. biol., I, 588 (1892).

3 "The Work of the Digestive Glands," translated by Thompson, second edition, p. ris, London (Igro).

Jour. Exp. Med., 10, 820 (1908). 
$250 \mathrm{cc}$., was only $4 / \mathrm{s}$ as great as that secreted upon the ingestion of $500 \mathrm{cc}$. of normal milk.

The most significant observation made by Foster and Lambert was to the effect, that the gastric juice secreted in the small stomach under the influence of water ingestion was not only increased in volume, but in its acid concentration as well. For example, when 300 grams of meat was fed a dog the acid value of the juice, at the fourth hour, expressed in terms of $0.1 \mathrm{~N} \mathrm{NaOH},{ }^{1}$ was 80 , whereas when $500 \mathrm{cc}$. of water were added to an equivalent quantity of meat the acid value rose to 138 . This high acid value was obtained notwithstanding the fact that the actual volume of juice was much increased under the influence of the water. It appears, therefore, that "when the secretion is abundant the acidity is much higher than when the secretion is scanty." The same phenomenon has been reported by Ketscher, ${ }^{2}$ one of Pavlov's associates. This variation in acidity was believed to be due to the fact that the rapidly secreted juice had less opportunity to come into contact with the alkaline gastric mucosa. On the basis of Ketscher's tests, Pavlov concluded that the juice, if prevented from coming into contact with the mucosa, would possess a similar acid concentration under all conditions, $i$. e., whether secreted slowly or rapidly. Foster and Lambert call attention to the fact that if this claim of a constant acid concentration, as stated by Pavlov, be true, then "the gastric secretion would form an exception to present ideas of glandular activity." On the basis of carefully performed tests, Foster and Lambert concluded that there was "a variation in percentage content of hydrochloric acid in gastric juice at different times during digestion."

That water stimulates the flow of gastric juice has again been demonstrated very recently by Sawitsch and Zeliony, ${ }^{3}$ who showed that the introduction of water in the pyloric portion of the stomach caused a flow of gastric juice in the fundus.

\section{Description.}

The subjects of the experiments herewith reported were two men " $\mathrm{E}$ " and " $W$," who had been used by one of us as subjects of other experiments. ${ }^{4}$ The particular data under consideration were obtained in connection with certain experiments reported by Mattill and Hawk. ${ }^{5}$ Reference may be made to these articles for a full description of experimental conditions surrounding the investigation.

1 The number of cubic centimeters required to neutralize roo cc. of gastric juice.

${ }^{2}$ Pavlov, Loc, cit.

3 Pfïger's Arch., r5o, 123 (1913).

4 Hawk, Arch. Int. Med., 8, 382 (rgr r). Hattrem and Hawk, Ibid., 7, 6ro (rgr r). Howe, Mattill and Hawk, Thrs Journal, 33, 568 (IgII). Mattill and Hawk, Ibid., 33, 1978 (I9II); 33, I999 (I9II); 33, 2019 (I9II).

- Mattill and Hawk, ThIs JoURNAL, 33, 1978, 1999, 2019 (191 I). 


\section{Discussion.}

In the course of one of the earlier of our studies on water drinking ${ }^{1}$ it was observed that the ingestion of an increased volume of water at meal-time caused an augmentation in the output of urinary ammonia. In the light of the findings of Pavlov and of Foster and Lambert, already cited, and of Walter ${ }^{2}$ and others on acid ingestion, it was believed that these high ammonia values might logically be interpreted as indicating that the water had stimulated the flow of gastric juice. The more efficient utilization of the protein constituents of the diet which accompanied these findings furnished further substantiation for the above interpretation.

Bearing the above points in mind the ammonia data obtained in the present investigation were given careful consideration in order to determine whether any further confirmation could be obtained for the hypothesis. already advanced. It was clearly apparent from a cursory examination of the data that the output of urinary ammonia had been markedly increased under the influence of an increased water ingestion. This fact, when taken into consideration in connection with the further fact that there was an accompanying better digestion and utilization of the ingested protein, ${ }^{3}$ was also considered as confirmatory evidence in favor of the hypothesis.

It so happened that " $E$ " and " $W$ " were each subjected to the influence of varying volumes of water, so-called moderate and copious water drinking, the accompanying ammonia determinations being made in each instance. The completed data indicated clearly that the increase in the ammonia excretion was more pronounced in the case of the larger water ingestion. When this question of relationship was considered more in detail it was found that during the periods of increased water ingestion there was, in each instance, an increase in the ammonia excretion which was directly proportional to the extra volume of water ingested. We arrived at this conclusion by means of the calculations embraced in a following paragraph:

Tably I.-Dati,y Ammonia Excretion as Influgnced by Watgr Drinking with MEALS.

Subject $W$.

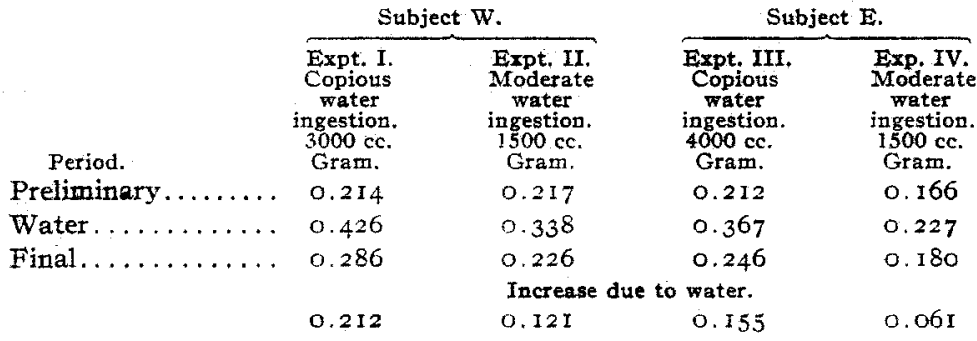

1 Fowler and Hawk, J. Exp. Med., 12, 388 (I910).

2 Arch. exp. Path., 7, 148 (1877).

3 Mattill and Hawk, THis Journal, 33, I 999 (1911). 
If we examine Table I, it will be noted, from a consideration of the data there summarized, ${ }^{1}$ that an ingestion of $3000 \mathrm{cc}$. of water at meal-time above that customarily ingested caused an average daily increase of 0.212 gram in the ammonia excretion of subject $W$, whereas an ingestion of 1500 cc. by this same subject caused an increase of only 0.121 gram in the ammonia output. In like manner, it will be observed that an addition of $4000 \mathrm{cc}$. to the water ingestion of subject $E$ caused an increase of 0.155 gram in the ammonia excretion, whereas when the volume of ingested water was $\mathrm{I} 500 \mathrm{cc}$. the ammonia output was augmented by only $0.06 \mathrm{I}$ gram.

Let us consider the data more in detail. We will first consider the data from the experiments on subject $W$. To facilitate the following of the relationship mentioned the data will be presented in logical mathematical sequence.

Moderate Water DRinking (Subject W).

Volume of milk ingested per day....................

Percentage of water in milk.......................

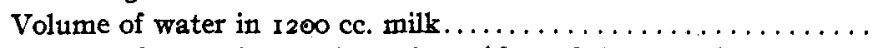

Volume of water ingested per day with meals in preliminary period

Total volume of water ingested per day with meals in preliminary period, $i . e$. , water plus water content of milk.............

Volume of increased water ingestion taken daily with mecls during water period $\ldots \ldots \ldots \ldots \ldots \ldots \ldots \ldots \ldots \ldots \ldots \ldots \ldots . . \ldots \ldots$

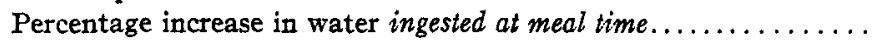

Copious Water Drinking (Subject W).

Volume of milk ingested per day .................. 1350 cc.

Volume of water in $1350 \mathrm{cc}$. milk.................. $1175 \mathrm{cc}$.

Volume of water ingested per day with meals in preliminary period $300 \mathrm{cc}$.

Total volume of water ingested per day with meals in preliminary period, $i$.. , water plus water content of milk............ $1475 \mathrm{cc}$.

Volume of increased water ingestion taken daily with meals during water period............................... $3000 \mathrm{cc}$.

Percentage increase in water ingested at meal time........... $203 \%$

Ratio between the percentage increase in the daily ingestion of water with meals during the water periods of the experiments on moderate (112\%) and copious $(203 \%)$ water drinking.........

Ratio between the increased output of ammonia under moderate ( 0.121 gram) and copious ( 0.212 gram) water drinking with meals............................... I : 1.75

Ratio between water ingestion and ammonia excretion....... I.8I: 1 .75

The similar ratio for Subject $E$ is $\ldots \ldots \ldots \ldots \ldots \ldots \ldots \ldots \ldots \ldots 2.66: 2.54$

We see from these ratios that there was practically a quantitative relationship between the water ingestion and the ammonia excretion. In other words, the increase in the ammonia excretion was directly proportional

1 The ammonia values for the individual days will be presented in a later paper in connection with other data on nitrogen distribution. 
to the increase in the volume of water ingested. We have interpreted the above findings as indicating that the water ingestion stimulated the flow of gastric juice thus causing the production of a greater quantity of hydrochloric acid and that this increased acid production was the forerunner of an increased ammonia output (see later discussion). The uniform relationship between the water ingestion and the ammonia output might perhaps be considered as indicating that there was an attempt on the part of the gastric cells to maintain a uniform acid concentration.

TABLE II.-WATER AND Ammonta Ratros.

\begin{tabular}{|c|c|c|c|}
\hline \multicolumn{2}{|c|}{ Subject $W$. } & \multicolumn{2}{|c|}{ Subject E. } \\
\hline $\begin{array}{l}\text { Expt: } \mathrm{I} \\
\text { Copious } \mathrm{H}_{2} \mathrm{O}\end{array}$ & $\begin{array}{c}\text { Expt. II. } \\
\mathrm{NH}_{3} \text { inc. (cop.) }\end{array}$ & $\begin{array}{l}\text { Expt. III. } \\
\text { Copious } \mathrm{H}_{2} \mathrm{O}\end{array}$ & $\begin{array}{l}\text { Expt. IV } \\
\text { NHz inc. (cop.) }\end{array}$ \\
\hline Moderate $\mathrm{H}_{2} \mathrm{O}$ & $\mathrm{NH}_{s}$ ine $(\mathrm{mod})$ & Moderate $\mathrm{H}_{8} \mathrm{O}$ & NHs inc. (mod.) \\
\hline $\mathrm{I}: \mathrm{I} .8 \mathrm{I}$ & I : I . 75 & $I: 2.66$ & I : 2.54 \\
\hline \multicolumn{4}{|c|}{ Increased $\mathrm{NH}_{3}$ per Ioo cc. $\mathrm{H}_{2} \mathrm{O}$ (grams). } \\
\hline $3000 \mathrm{cc} \mathrm{Hg}_{2} \mathrm{O}$ & 1500 cc. $\mathrm{H}_{2} \mathrm{O}$ & 4000 ec. $\mathrm{H}_{2} \mathrm{O}$ & $1500 \mathrm{cc} . \mathrm{F}_{2} \mathrm{O}$ \\
\hline $0.007 \mathrm{I}$ & $0.008 \mathrm{r}$ & 0.0039 & 0.0040 \\
\hline
\end{tabular}

When we compute the amount of ammonia excreted for every increase of roo cc, in the water ingestion we find a significant relationship. The values thus secured are shown in the lower portion of the above table. In the tests made upon subject $\mathrm{W}$ it will be seen that each $100 \mathrm{cc}$. of the three liters of water added to the water ingestion during the interval of copious water drinking caused an increase of $0.007 \mathrm{I}$ gram in the ammonia output, whereas when the water ingestion was increased only $1500 \mathrm{cc}$. each Ioo cc. augmented the ammonia excretion 0.0081 gram. A similar relationship held for subject $E$. In other words, when we calculate the increased ammonia excretion upon the basis of a $100 \mathrm{cc}$. increase in the water ingestion, we find that the excretion was a trifle higher during moderate water drinking than during the period of copious water ingestion. These findings might be interpreted as indicating that after a certain limit had been reached in the water ingestion, each succeeding roo $\mathrm{cc}$. of water was less efficient as a stimulating factor than were the roo cc. portions ingested before the limit above mentioned had been reached.

When we compare the data from the two subjects we obtain interesting information regarding the reaction of different individuals to similar stimuli. In the moderate water drinking tests, for example, Subjects $\mathrm{E}$ and $\mathrm{W}$ each increased their water ingestion by ${ }_{15} 50 \mathrm{cc}$. If the ammonia values be consulted it will be noted that the ammonia output was increased 0.121 gram in the case of $W$ and 0.061 gram in the case of $E$. In other words, identical stimuli proved twice as efficient in the organism of $\mathrm{W}$ as in that of $\mathrm{E}$. A similar type of telationship is in evidence in connection with the tests on copious water drinking. Here it was demonstrated that $4000 \mathrm{cc}$. of water in E's organism was only about $73 \%$ as 
efficient as a stimulatory factor as was $3000 \mathrm{cc}$. in W's organism. ${ }^{1}$ It is entirely logical to infer furthermore that the response of the same individual to identical stimuli will not always be the same. For example, it is entirely possible that three liters of water would not, under all conditions, cause sufficient stimulation of the gastric secretion of $W$ to cause an increase of 0.212 gram in the output of ammonia. In other words, we do not wish to be understood as claiming that a variation in the water ingestion of an individual will, of necessity, be accompanied by a quantitative relationship between the associated ammonia excretions.

In order to substantiate our acceptance of the increased ammonia output as an index of a stimulated gastric secretion, permit us to make certain potent citations from the literature. In the first place we would call attention to various investigations upon man and the lower animals which have demonstrated clearly that the feeding of mineral acids and acid salts is followed by an increased excretion of urinary ammonia.

The balance of acids and bases in the animal organism has a very pronounced influence upon the extent of the ammonia output. Experiments have demonstrated conclusively that the acids present in the organism cause an increase in the excretion of ammonia, irrespective of whether such acids are introduced from without or are formed in the processes of intermediary metabolism. These acids have been considered as neutralizing a part of the ammonia and thus withdrawing it from participation in the formation of urea. Walter ${ }^{2}$ was the first to demonstrate that acids possessed this influence. This investigator fed hydrochloric acid to dogs and secured an increased output of urinary ammonia. Hallervorden, ${ }^{3}$ after ingesting $2.8 \mathrm{I}$ grams of hydrochloric acid on each of two days, secured an increase in the ammonia output aggregating 2.035 grams for a five-day interval. Kowalevsky and Salaskin ${ }^{4}$ fed 6 grams of hydrochloric acid to a fasting goose and increased the percentage of the total nitrogen excreted as ammonia nitrogen from $14.98 \%$ to $33.36 \%$. Certain experiments by Eppinger ${ }^{5}$ and Winterberg $^{6}$ indicate that an increased ammonia elimination also follows the administration of mineral acids to rabbits. Kettner ${ }^{7}$ and Pohl and Münzer, ${ }^{8}$ on the other hand, failed to obtain such an increase in the case of herbivora.

${ }^{1} \mathrm{E}$ was receiving $20.4 \mathrm{cc}$. water per $\mathrm{kg}$. body weight; $\mathrm{W}$ was receiving $23.6 \mathrm{cc}$.

${ }^{2}$ Arch. exp. Path., 7, I48 (1877).

${ }^{3}$ Ibid., Io, 125 (1878).

${ }^{4} Z$. physiol. Chem., 35, 552 (1902).

- Z. exp. Path., 3, 530 (I go6).

' $Z$. physiol. Chem., 25, 202 (I898).

'Arch. exp. Path., 47, I78 (1907).

${ }^{8}$ C. Physiol., 20, 232 (1906). 
It has been suggested by Hallervorden ${ }^{1}$ and Coranda ${ }^{2}$ that man takes an intermediate position between carnivora and herbivora so far as the intensity of the stimulatory power of ingested acid upon the urinary ammonia output is concerned.

That the daily ammonia output may be taken as an index of the course of diabetic acidosis is well recognized. Müller was the first to demonstrate that a pronounced increase in the ammonia excretion followed extensive acidosis. ${ }^{3}$ Cases of diabetes mellitus occasionally excrete from 7 to 12 grams of ammonia per day, whereas the normal output is approximately 0.7 gram. $^{4}$

It is, furthermore, a well-known fact in normal nutrition that there is an increase in the urinary ammonia output when a high protein diet is ingested. This is principally due to the excessive quantity of sulfuric acid formed in the oxidation of such a diet. A portion of this ammonia may also arise from increased intestinal putrefaction.

The above citations from normal and pathological metabolism in which there is an increased açid production in the body, and the experiments on man and lower animals in which mineral acids have been ingested, all indicate that such acid production or ingestion is followed by an increased output of ammonia in the urine. Therefore, inasmuch as it has been shown by experiment that water stimulates the flow of gastric juice and that consequently there is an augmented secretion of acid, we feel warranted in advancing the hypothesis that the increased ammonia excretion which accompanies the drinking of water at meal time is brought about through the stimulatory power of the ingested water.

In view of the recent claim of Folin and Denis that the ammonia of the portal circulation has its origin in large part in putrefactive processes taking place in the large intestine, it might be argued that the drinking of water has caused increased putrefaction. From this standpoint, then, the high ammonia values which the urines in our water experiments possess might be considered to be an index of increased intestinal putrefaction. Fortunately, however, the course of intestinal putrefaction, in the experiments in question, was followed by Hattrem and Hawk. ${ }^{5}$ They found the output of urinary indican much decreased during the period of water drinking. If indican is a true index of intestinal putrefaction we must conclude that the high ammonia values occurred coincidently with a decreased intestinal putrefaction and that the major part, at least, of the ammonia did not have a putrefactive origin.

${ }^{1}$ Arch. exp. Path., ro, 125 (1878).

I Ibid., 12, 76 (1880).

s Lusk, J. Am. Med. Assoc., Dec, r7, r9ro.

"Magnus-Levy, v. Noorden's Handb. d. Path. d. Stoffwechsel, I, p. Ir5.

${ }^{5}$ Hattrem and Hawk, Arch. Inl. Med., 7,610 (191 I). 


\section{Conclusions.}

The ingestion of water at meal time by two men was accompanied by an increase in the excretion of ammonia which was directly proportional to the extra volume of water ingested. Inasmuch as certain experiments have demonstrated that water stimulates the flow of an acid gastric juice and as certain other experiments have demonstrated that the formation of acid in the body or the introduction of acid from without produces an increase in the urinary ammonia excretion, we feel justified in assuming that the increase in the ammonia excretion observed in our experiments was due directly to the stimulation of gastric secretion by the ingested water.

The uniform relationship between the water ingestion and the ammonia output might perhaps be considered as indicating that there was an attempt on the part of the gastric cells to maintain a uniform acid concentration.

If we calculate the increased ammonia excretion, on the basis of a Ioo cc. increase in the water ingestion, we find that the excretion was a trifle higher during moderate water drinking than during copious water drinking. This would indicate that after a certain limit had been reached in water ingestion each succeeding I0O cc. of water was less efficient as a stimulating factor than were the roo cc. portions ingested before the limit above mentioned had been reached.

That different organisms may respond differently to identical stimuli was indicated by the fact that the increase in the ammonia output of one subject was $100 \%$ greater than that of the other subject, notwithstanding the fact that the increase in the water ingestion was the same in each instance.

That the increase in the ammonia excretion did not arise from intestinal putrefaction was indicated by the finding of lowered indican values during the period of high water ingestion.

Peil,adel,phia, Pa.

[CONTRIBUTION FROM STEVENS INSTITUTE OF TECHNOLOGY.]

\section{A REVIEW OFITHE PIONEER WORK ON THE SYNTHESIS OF RUBBER. ${ }^{1}$ \\ By Francis J. Pond. \\ Received November 7, 1913.}

At a meeting of the chemical society of Heidelberg on May 19, 1906, Prof. E. Knoevenage ${ }^{2}$ presented a paper in which he described two new hydrocarbons, $\mathrm{C}_{6} \mathrm{H}_{10}$, belonging to the $\Delta^{1,3}$-butadiene series. One of these hydrocarbons was found to yield a dimolecular polymeride, $\mathrm{C}_{12} \mathrm{H}_{20}$,

${ }^{1}$ Read before the New York Section of The American Chemical Society, Oct. Io, I9I3.

2Z. angew. Chem., [2] r9, 1330. 